\title{
Impacts of Plug-in Hybrid Vehicles and Combined Heat and Power Technologies on Electric and Gas Distribution Network Losses
}

\author{
Salvador Acha, Member, IEEE, Tim C. Green, Senior Member, IEEE, and Nilay Shah
}

\begin{abstract}
Distribution network operators (DNOs) require strategies that can offset the tradeoffs new embedded technologies have on their assets. This paper employs modelling to show that through control device manipulation, gas and electric (G\&E) network operators can influence savings in energy losses under the presence of plug-in hybrid vehicles (PHEVs) and combined heat and power technologies (CHPs). An integrated gas and electric optimal power flow (OPF) tool is introduced to undertake various case studies. The OPF tool evaluates the technical impacts experienced in the networks when DNOs apply a "plug and forget" operation strategy and then compares the results against a "loss minimisation" strategy. Results show the benefits in applying different strategies are more considerable in electric networks than in gas networks. The study corroborates that an integrated G\&E analysis offers a fresh perspective for stakeholders in evaluating energy service networks performance under different operation strategies.
\end{abstract}

Index Terms-Combined heat and power, distributed generation, distribution network operation, natural gas, optimal power flow, plug-in hybrid electric vehicles, power losses.

\section{NOMENCLATURE}

$b_{i j} \quad$ susceptance, element $i j$

$E_{\text {nodes }} \quad$ number of electric nodes

$g_{i j} \quad$ conductance, element $i j$

$I_{i j} \quad$ current flowing in element $i j$

$\mathrm{G}_{\text {nodes }} \quad$ number of gas nodes

$K_{\text {com }} \quad$ compressor efficiency factor

$\mathrm{MWh}_{\mathrm{el}} \quad$ electric mega-watt hour

$\mathrm{MWh}_{\mathrm{th}} \quad$ thermal mega-watt hour

$n \beta \quad$ number of time periods

nc number of compressor stations

$n l \quad$ number of line elements

np number of pipe elements

nt number of on-load tap changers

$P e_{i j} \quad$ electric power in line element $i j$

$P e_{j i} \quad$ electric power in line element $j i$

The authors wish to acknowledge CONACyT and BP for their financial support of this research investigation.

S. Acha is with the Department of Electrical Engineering, Imperial College, London, UK SW7 2AZ (e-mail: salvador.acha@imperial.ac.uk).

T. Green is with the Department of Electrical Engineering, Imperial College, London, UK SW7 2AZ (e-mail: t.green@imperial.ac.uk).

$\mathrm{N}$. Shah is with the Department of Chemical Engineering, Imperial College, London, UK SW7 2AZ (e-mail: n.shah@imperial.ac.uk).
$P e_{i n j, \alpha}$

$P e_{\text {gen, } \alpha}$

$P e_{\text {load, } \alpha}$

$P e_{L, i j}$

$P e_{L, \alpha \beta}$

$P g_{\text {com }}$

$P g_{\text {com }, \alpha \beta}$

$P g_{i j}$

$P g_{i j c}$

$P g_{i n j, \alpha}$

$P g_{g e n, \alpha}$

$P g_{\text {load, } \alpha}$

$P g_{L, \alpha \beta}$

$\mathrm{PO}_{i}$

$\mathrm{PO}_{\text {ic }}$

$\mathrm{Po}_{j}$

$\mathrm{Po}_{\alpha}$

$P o_{\alpha, \max }$

$P o_{\alpha, \min }$

$r$

$r_{\alpha}$

$r_{\alpha, \max }$

$r_{\alpha, \text { min }}$

$|t|$

$|t|_{\alpha \beta}$

$|t|_{\alpha}$

$|t|_{\alpha, \max }$

$|t|_{\alpha, \min }$

$V_{i}$

$V_{j}$

$V_{\alpha}$

$V_{\alpha, \max }$

$V_{\alpha, \text { min }}$

$y_{i j}$

$\alpha$

$\beta$

$\theta_{i}$

$\theta_{j}$

$\tau$ electric power injection at node $\alpha$ electric power generation at node $\alpha$ electric power load at node $\alpha$ electric power loss in line element $i j$ electric power loss in line element $\alpha$ at time $\beta$ compressor load

compressor load of unit $\alpha$ at time $\beta$ inbound gas power in pipe element $i j$ outbound gas power in pipe element $i j$ gas power injection at node $\alpha$ gas power generation at node $\alpha$ gas power load at node $\alpha$ gas power loss in pipe element $\alpha$ at time $\beta$ inbound pressure level at node $i$ outbound pressure level at node $i$ pressure level at node $j$ pressure level at node $\alpha$ upper limit pressure level at node $\alpha$ lower limit pressure level at node $\alpha$ compressor operation ratio operation ratio of compressor unit $\alpha$ upper ratio limit of compressor unit $\alpha$ lower ratio limit of compressor unit $\alpha$ tap magnitude of OLTC tap magnitude of OLTC unit $\alpha$ at time $\beta$ tap magnitude of OLTC unit $\alpha$ upper tap magnitude limit of OLTC unit $\alpha$ lower tap magnitude limit of OLTC unit $\alpha$ voltage at node $i$ voltage at node $j$ voltage at node $\alpha$ upper limit voltage at node $\alpha$ lower limit voltage at node $\alpha$ admittance, element $i j$

index for unit index for time angle at node $i$ angle at node $j$ phase shifting angle of OLTC 


\section{INTRODUCTION}

$\mathrm{U}$ RBAN energy service networks, which in the case of this paper refers only to natural gas and electrical infrastructure, have traditionally been designed and operated separately from one another. However, there are conditions that could arguably propose this situation might change in the near future. This is because coordinated efforts between the various energy stakeholders might be deemed necessary in order to obtain greater benefits from planning and operation strategies. One of the reasons for this strategic change is the continuous increasing energy demand in urban areas that has the potential of stressing the infrastructures; consequently, increasing energy losses in the networks [1]. This fact, combined with the environmental concerns regarding climate change are drivers that have created a consensus to promote the use of technologies which are more efficient in fuel conversion and that employ cleaner energy resources to tackle $\mathrm{CO}_{2}$ emissions [2]. Thus, two promising technologies that can play a significant role in meeting the challenges for efficient use of energy resources while at the same time reducing emissions are CHP and PHEV technologies [3], [4]. This "paradigm" shift from traditional energy provision enables the coupling of natural gas and electrical systems for a greater efficiency in heat and power delivery [5].

Various CHP engine technologies exist in the market today with capacities ranging from industrial and commercial applications up to residential consumers [6]. These devices are usually fuelled by natural gas and vary widely in their efficiency and heat to power ratio production [7]. Some technical benefits CHP brings to distribution networks are the savings in energy loss transmission as well as a reduction in the supply at moments of peak demand [8]. Many technical studies regarding CHP impacts on distribution networks have been reported in the literature, they generally focus on power losses, allocation of generators, and connectivity issues. Publications on the above issues include [9], [10], and [11].

Meanwhile, plug-in hybrid electric vehicles have been gaining much public attention due to both the high prices of petrol and the high $\mathrm{CO}_{2}$ emissions conventional vehicles produce [12]. PHEVs have the potential of becoming mobile agents that could operate as either a load or storage units throughout the electrical networks. These agents would then be able to provide power back to the grid under different charging and discharging scenarios, usually acting upon economic signals [13]. Due to the above benefits, the auto industry is working relentlessly to release the first PHEV models into the market [14]. Therefore, many publications on the technical impacts of this technology on the electrical grid have appeared recently. [15], [16] and [17] are just a sample of research that deal with various charging scenarios and the costs associated with the power demand that will be needed to satisfy the transport sector.

The above circumstances create the opportunity to explore the tradeoffs embedded technologies can bring in terms of energy savings when a coordinated effort between gas and electric network operators wish to enhance the performance of their infrastructures. Hence, the network interdependency is portrayed in this paper by modelling the operation of control devices under various penetration scenarios of CHP and PHEV. This is done with the purpose of determining how different control device operation strategies affect network losses in each infrastructure. The control mechanism in the electrical network is the on-load tap changer (OLTC), while the control unit in the gas network is the compressor. Figure 1 illustrates the components which are considered essential to model in order to obtain significant contributions in this area of research.

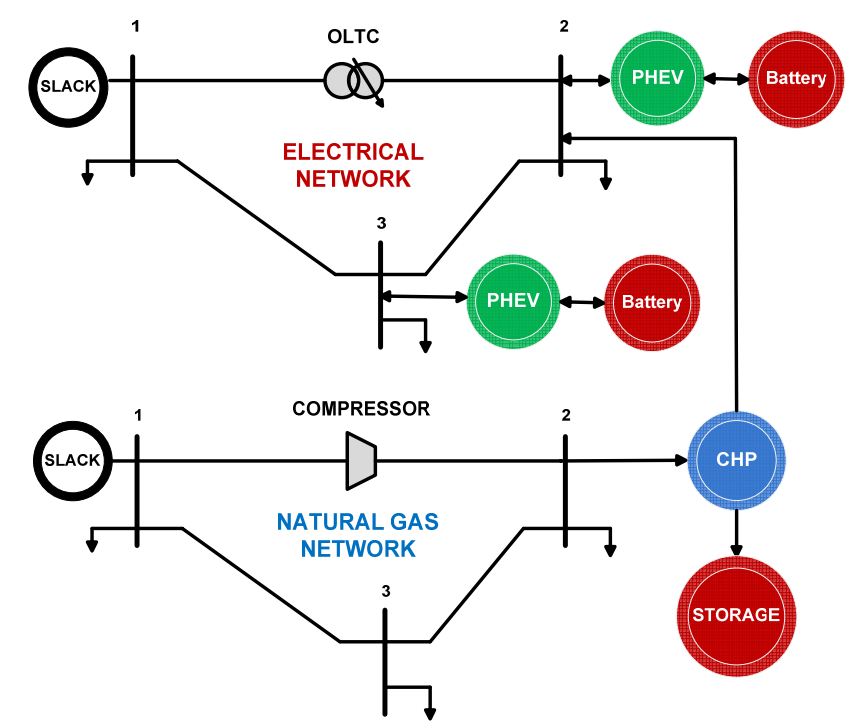

Fig. 1. Energy networks coupled through new technologies, such as PHEV and CHP, might increase the efficiency in power provision.

References [18], [19], [20], [21] are basic in this string of research since they present integrated power flow models for natural gas and electricity networks. However, they optimise on operation costs and do not consider either exploring loss minimisation or including PHEV in their models. Publications that deal with assessments on how PHEV impacts on the electric grid can be modified with the presence of distributed generation, storage facilities, and the aid of control devices in the networks are scarce in the literature. Paper [22] continues with some ideas from [21] but concentrates more on dispatch strategies for the reliable supply of energy to the fleet of vehicles in an urban area through a concept defined as PHEV managers. Information [23] elaborates a national model where multiple renewable sources and electric vehicle technologies form an integral part of the power system. The study is performed at a high level while giving indications of the best moment during the day to charge the vehicles. Nevertheless, it does not cover the role network operators could play in improving the delivery of energy at the distribution level.

To address the challenge of analysing the behaviour of control devices on gas and electric distribution networks this paper introduces an integrated optimal power flow model. In this OPF model the CHP units serve as a link between both networks while PHEV agents stress the power network according to their charging strategy. Basic gas and electric 
power flow concepts are not covered in this paper since these issues were addressed previously [24]. It is important to note that in this paper all the attention is focused on active power transfer. The reactive power flow was determined and an adequate balance was observed. Therefore, no mention is done regarding reactive power in the results section.

This work begins by explaining how to model the control devices in each network; OLTC in electrical systems and compressors in gas systems. Secondly, the optimal power flow formulation is presented in which a "plug and forget" scenario is compared against a "minimum loss" scenario. Then the document follows by presenting various case studies that show how DNOs through their control strategies influence energy losses in each infrastructure. Results from the simulations demonstrate the relevance of the optimal power flow tool in evaluating and quantifying the tradeoffs DNOs might face in the near future.

\section{Control Devices In ENERgy Networks}

Both gas and electrical networks have control devices that regulate their key operating variables; pressure and voltage values respectively. These devices operate with the purpose of maintaining their respective systems within operational boundaries which will guarantee a good quality in the delivery of energy. In this section an explanation of the equations used to model these devices is described.

\section{A. On Load-Tap Changer in Electrical Networks}

Electric networks use a tap-changing mechanism within a power transformer to enable a range of voltage magnitude regulation at one of their terminals. This is achieved by producing a variable voltage magnitude with respect to the voltage magnitude at the output winding [25]. Figure 2 shows a simple representation of an OLTC.

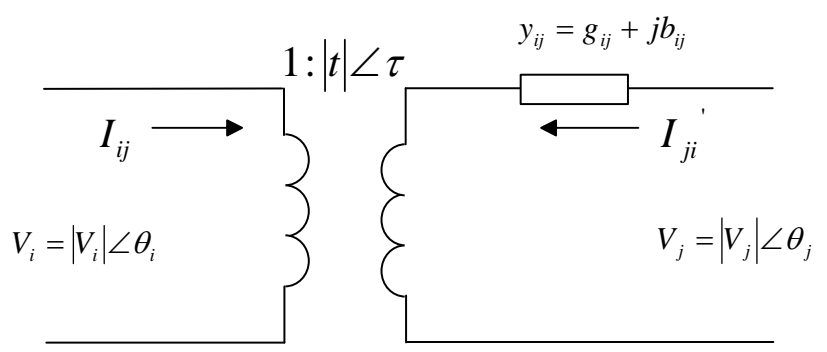

Fig. 2. Representation of an on-load tap-changer transformer (OLTC).

The equations used to represent active power flow in an OLTC element that connects node $i$ to $j$ are

$$
\begin{gathered}
P e_{i j}=\left|V_{i}\right|^{2}|t|^{2} g_{i j}-\left|V_{i}\right|\left|V_{j}\right||t| g_{i j} \cos \left(\theta_{i}-\theta_{j}+\tau\right)-\left|V_{i}\right|\left|V_{j}\right||t| b_{i j} \sin \left(\theta_{i}-\theta_{j}+\tau\right) \\
P e_{j i}=\left|V_{j}\right|^{2} g_{i j}-\left|V_{j}\right|\left|V_{i}\right| t\left|g_{i j} \cos \left(\theta_{j}-\theta_{i}-\tau\right)-\right| V_{j}|| V_{i}|| t \mid b_{i j} \sin \left(\theta_{j}-\theta_{i}-\tau\right)
\end{gathered}
$$

The power losses for element $i$ to $j$ is expressed as

$$
P e_{L, i j}=\left|V_{i}\right|^{2}|t| g_{i j}+\left|V_{j}\right|^{2} g_{i j}-2\left|V_{i}\right|\left|V_{j}\right||t| g_{i j} \cos \left(\theta_{i}-\theta_{j}+\tau\right)
$$

Equation 3 shows that losses in the element can change by modifying the tap magnitude value. Once these equations are introduced into the model the effects that OLTCs can have on electric networks can be quantified.

\section{B. Compressor Station in Gas Networks}

Gas systems employ compressor stations to provide the pressure needed to transport gas more effectively from one location to another. Compressors require power to increase the pressure levels throughout the network. This power is usually supplied by a gas turbine. Thus, when the compressor is in operation it is modelled as an additional load in the system. Figure 3 shows a simple illustration of a compressor.

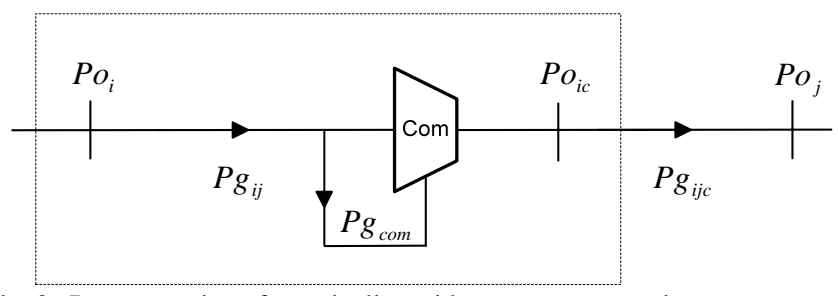

Fig. 3. Representation of gas pipeline with a compressor station.

The following equations taken from [26] calculate the amount of gas the compressor will use when active

$$
\begin{gathered}
P g_{\text {com }}=K_{\text {com }} P g_{i j c}\left(P o_{i c}-P o_{i}\right) \\
r=\frac{P o_{i c}}{P o_{i}}
\end{gathered}
$$

Equation 4 determines the load demand of the compressor in order to increase the outbound pressure at node $i$ with respect to its inbound pressure. Equation 5 specifies the compressor ratio which is analogous to the tap magnitude variable for electrical networks. Once these equations are introduced into the model the effects that compressors can have on gas networks can be calculated.

\section{GAS AND ELECTRIC OPF FORMULATION}

An optimal power flow problem extends the conventional steady-state power flow problem in which the goal is to determine the operating conditions of the network at a given time. However, the novelty in the OPF solution resides in obtaining the best possible value for an objective function while respecting the system operating constraints.

For an integrated gas and electric network analysis we represent both systems separately for a better interpretation. The test network used to perform the studies can be seen in figure 4. CHP units are modelled as a positive load in the gas system and as a negative load (power injections) in the electrical system. Concurrently, PHEV units are only seen as an additional (positive) load in the electric network. Storage technologies are not modelled in this publication. In consequence, the PHEVs are not able to provide power back to the grid. 


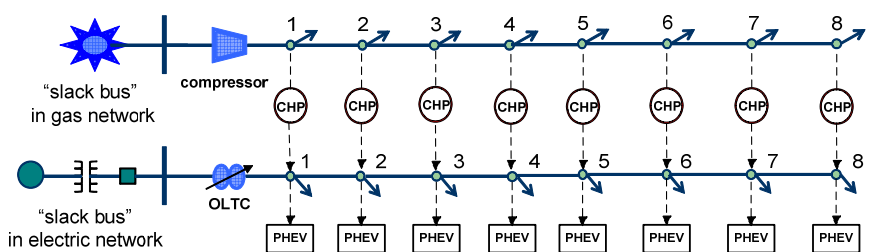

Fig. 4. Depiction of the radial networks used for the case studies.

The scope of this research is to develop a model that is able to compare how the network control devices operate under different strategies with the presence of embedded technologies. This aspect results in questions of optimal system operation, such as:

- What are the impacts in terms of energy losses that CHP and PHEV technologies can have on energy service networks under a "plug and forget" scenario?

- How much energy savings can be achieved if we coordinate gas and electrical control devices in order to "minimise losses" in the service networks?

In the following sections the formulations of the objective functions and optimality conditions employed in this research are explained.

\section{A. Plug and Forget vs. Loss Minimisation}

Two operation strategies are used in this research in order to have a broad picture of the effects DNOs can have on energy losses.

The reference strategy, a.k.a. business as usual, is labelled as the "plug and forget" scenario. The conditions for this problem consist in minimising the use of the control devices while supplying the demand in each node and guaranteeing the operational boundaries are met. This implies network operators will not bother using their control devices unless it is absolutely necessary. Hence, in gas networks the objective function minimises the compressor gas consumption. While for electrical networks the tap magnitude being as close as possible to a fix value is the objective function.

The second strategy, a.k.a. pro-active mode, on the other hand is known as the "loss minimisation" scenario. Here the DNOs have the freedom to use their control devices in order to reduce losses originated during the delivery of energy to consumers. Therefore, in gas systems the objective function concentrates on reducing the losses that are the product of the flow through a pipe multiplied by the pressure drop between nodes. While the approach taken for the objective function in the electrical counterpart is the difference between the total generation and the total load in the system.

\section{B. Problem Statement for the Integrated Power Flow}

The mathematical formulation of the gas and electric OPF can be expressed as

For plug and forget

$$
\min \sum_{\alpha=1}^{n c} P g_{c o m, \alpha \beta}+\min \sum_{\alpha=1}^{n t}\left(|t|_{\alpha \beta}-1\right) \quad(\beta=1, \ldots ., n \beta)
$$

For loss minimization

$$
\min \sum_{\alpha=1}^{n p} P g_{L, \alpha \beta}+\min \sum_{\alpha=1}^{n l} P e_{L, \alpha \beta} \quad(\beta=1, \ldots ., n \beta)
$$

Subject in each time period $\beta$ to

$$
\begin{array}{cc}
P e_{\text {gen }, \alpha}-P e_{\text {load }, \alpha}-P e_{\text {inj, } \alpha} & \left(\alpha=1, \ldots ., E_{\text {nodes }}\right) \\
V_{\alpha, \min } \leq V_{\alpha} \leq V_{\alpha, \max } & \left(\alpha=1, \ldots ., E_{\text {nodes }}\right) \\
|t|_{\alpha, \min } \leq|t|_{\alpha} \leq|t|_{\alpha, \max } & (\alpha=1, \ldots ., n t) \\
P g_{\text {gen }, \alpha}-P g_{\text {load }, \alpha}-P g_{\text {inj }, \alpha} & \left(\alpha=1, \ldots ., G_{\text {nodes }}\right) \\
P o_{\alpha, \min } \leq P o_{\alpha} \leq P o_{\alpha, \max } & \left(\alpha=1, \ldots ., G_{\text {nodes }}\right) \\
r_{\alpha, \min } \leq r_{\alpha} \leq r_{\alpha, \max } & (\alpha=1, \ldots ., n c)
\end{array}
$$

Although the objective functions might be different, the constraints are the same for both OPF problems. Equation (6) specifies the optimal state of the network for the plug and forget scenario. Term (7) describes the minimum loss criterion the solver must follow to reduce energy losses throughout the networks. Equation (8) refers to active power flow conservation per node. Equation (9) represents voltage limits at nodes, while (10) specifies the range of operation for the tap changer. Expression (11) is the natural gas flow conservation at each node. Equation (12) defines the pressure limits per node, and (13) defines the compressor operation range.

In practical OPF solutions the following tests are done to verify a feasible solution has been obtained [27]:

- Power mismatches are within the specified tolerance.

- The inequality constraints are satisfied.

- The gradient vector is zero.

- Further reduction in the objective function is only possible if constraints are breached.

\section{CASE StUdiES}

Various case studies were simulated with the purpose of assessing the different OPF formulations described in the past section. The original gas and electric 24 hour load profile has been provided from a residential area during a typical UK winter day [10].

\section{A. Case Descriptions}

Table 1 shows a summary of the simulated case studies. Case 1 is the reference case where no embedded technologies are present in the networks. Four additional case studies were carried out after case 1 which mainly vary in two aspects with respect to each other, these are:

- The penetration of PHEV and CHP embedded in the networks.

- The charging strategy of PHEV units.

A solid oxide fuel cell is the CHP technology modelled in these studies. This is because they appear to be the most promising for residential use due to their high efficiency and 1:1 heat to power production ratio which increases the 
operation time of the unit throughout the year [28]. In all the case studies CHPs operate under thermal requirements and the electrical power generated is considered an added benefit. If customers do not have CHP it is assumed boilers with $80 \%$ efficiency satisfy the remaining heat demand. The CHP capacity and efficiency parameters are taken from [24].

The PHEV charging profiles modelled in these studies are obtained from [17]. It is assumed that these vehicles have a constant charge rate of $1.4 \mathrm{~kW}$ and the charging time for a completely discharged battery is approximately 6 hours. The charging modes used in the study are uncontrolled (without restrictions) and delayed (night charge only).

TABLE I

DESCRIPTION OF CASE STUDIES PLUG AND Forget VS. LOSS MinimisATION

\begin{tabular}{|c|c|c|c|}
\hline $\begin{array}{c}\text { Case } \\
\text { number }\end{array}$ & $\begin{array}{c}\text { \% of PHEV and } \\
\text { CHP penetration }\end{array}$ & $\begin{array}{c}\text { PHEV charging } \\
\text { mode }\end{array}$ & $\begin{array}{c}\text { CHP operation } \\
\text { mode }\end{array}$ \\
\hline Case 1 & $0 \%$ & None & None \\
\hline Case 2 & $10 \%$ & Uncontrolled & Heat led \\
\hline Case 3 & $10 \%$ & Delayed & Same as case 2 \\
\hline Case 4 & $30 \%$ & Uncontrolled & Heat led \\
\hline Case 5 & $30 \%$ & Delayed & Same as case 4 \\
\hline
\end{tabular}

\section{B. Results}

The integrated OPF problem consists of a non-linear optimisation with linear and non-linear equality and inequality constraints which has been successfully coded in the gPROMS $^{\mathrm{TM}}$ software [29]. The OPF was tested using the 8 node urban radial network from figure 4. The network features are representative since they have been taken from specialised distribution network reports [30], [31]. The substation voltage is $11 \mathrm{kV}$, while the base pressure is 7 bar.

Results in the gas network show that the presence of CHP has mild effects on key operating parameters such as load factor. This could be due to the high power demand in the winter season. As expected, the network losses do increase slightly when CHP penetration increases. However, it draws attention that under the minimum loss criteria the energy saved is close to $0.22 \%$ in each case. Table 2 displays a summary of the gas network results.

TABLE II

GAS NETWORK RESULTS

\begin{tabular}{|c|c|c|c|c|c|c|}
\hline \multirow{2}{*}{} & \multicolumn{3}{|c|}{ Plug and Forget } & \multicolumn{3}{c|}{ Loss Minimisation } \\
\cline { 2 - 7 } & $\begin{array}{c}\text { Load } \\
\text { factor (\%) }\end{array}$ & $\begin{array}{c}\text { Loss } \\
(\%)\end{array}$ & $\begin{array}{c}\text { Control } \\
\text { use }\end{array}$ & $\begin{array}{c}\text { Load } \\
\text { factor (\%) }\end{array}$ & $\begin{array}{c}\text { Loss } \\
(\%)\end{array}$ & $\begin{array}{c}\text { Control } \\
\text { use }\end{array}$ \\
\hline Case 1 & 44.13 & 4.81 & 2 & 44.18 & 4.59 & 24 \\
\hline Case 2 & 44.10 & 4.92 & 2 & 44.14 & 4.70 & 24 \\
\hline Case 4 & 44.01 & 5.15 & 3 & 44.07 & 4.92 & 24 \\
\hline
\end{tabular}

Results in the electric network show a $1.9 \%$ reduction in energy losses (as an average) when the OLTC operate under the minimum loss criteria. Additionally, the peak loads in cases 3 and 5 are less than in case 1, which combined with a higher base load, translates into an increased load factor. During the "plug and forget" scenario losses are higher when PHEV charge in the delayed strategy when compared to the uncontrolled strategy. However, this trend is the opposite when the objective function is set for "loss minimisation". These results imply that although night charging of PHEV will be beneficial in not increasing peak demand it will incite higher losses in the networks unless intelligent control strategies are implemented. Finally, in case 5 the "plug and forget" scenario yields no use of the OLTC during the day because CHP power injections are quite substantial in reducing the peak load. Table 3 displays a summary of the electric network outputs.

TABLE III

ELECTRIC NETWORK RESULTS

\begin{tabular}{|c|c|c|c|c|c|c|}
\hline & \multicolumn{3}{|c|}{ Plug and Forget } & \multicolumn{2}{c|}{ Loss Minimisation } \\
\cline { 2 - 7 } & $\begin{array}{c}\text { Load } \\
\text { factor (\%) }\end{array}$ & $\begin{array}{c}\text { Loss } \\
(\%)\end{array}$ & $\begin{array}{c}\text { Control } \\
\text { use }\end{array}$ & $\begin{array}{c}\text { Load } \\
\text { factor (\%) }\end{array}$ & $\begin{array}{c}\text { Loss } \\
(\%)\end{array}$ & $\begin{array}{c}\text { Control } \\
\text { use }\end{array}$ \\
\hline Case 1 & 57.73 & 5.39 & 4 & 56.68 & 3.65 & 24 \\
\hline Case 2 & 57.27 & 5.21 & 4 & 56.28 & 3.54 & 24 \\
\hline Case 3 & 59.40 & 5.38 & 3 & 58.18 & 3.47 & 24 \\
\hline Case 4 & 56.45 & 5.12 & 3 & 55.42 & 3.35 & 24 \\
\hline Case 5 & 60.99 & 5.70 & 0 & 61.77 & 3.20 & 24 \\
\hline
\end{tabular}

Figure 5 and 6 represent the power demand variations seen from the supply point as PHEV and CHP technologies gain presence in the networks. Power profiles like the ones presented here could easily become less predictable as embedded technologies gain more presence at the lower levels of the network without a predefined operation strategy. Furthermore, it would be interesting to asses what variations might occur to these profiles once storage capabilities are included into the present OPF model.

\section{Winter power load profile at the supply point}

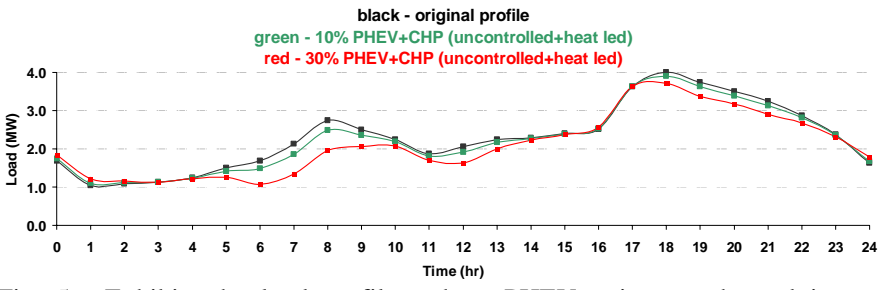

Fig. 5. Exhibits the load profiles where PHEV units are charged in an uncontrolled way while CHP devices are operated on thermal demand.

\section{Winter power load profile at the supply point}

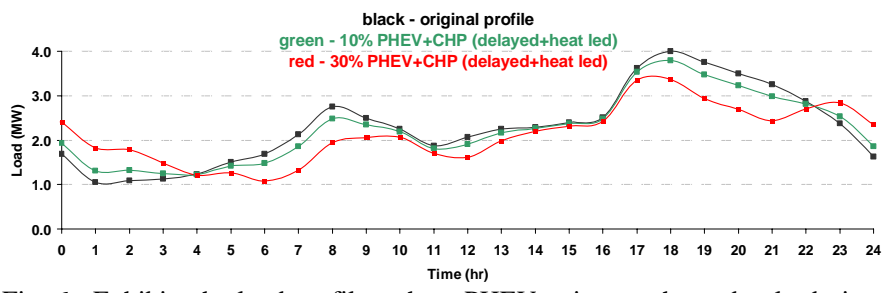
Fig. 6. Exhibits the load profiles where PHEV units are charged only during the night while CHP devices are used following thermal demand.

Figures 7 and 8 depict the net effect CHP and PHEV can have on the grid supply point during the winter day being assessed for cases 4 and 5 . The contributions of the CHP generation would seem to be beneficial in reducing distribution losses. However, further research and attention must be given to this fact since there could be times that the excess of energy could increase losses on the network [32]. 
Furthermore, CHP deployment could allow developing new charging scenarios for PHEV units. To address the above issues stakeholders might need to invest in monitoring and demand side management applications to find benefits in these unfamiliar power fluctuations.

PHEV + CHP Winter power load profile at the supply point

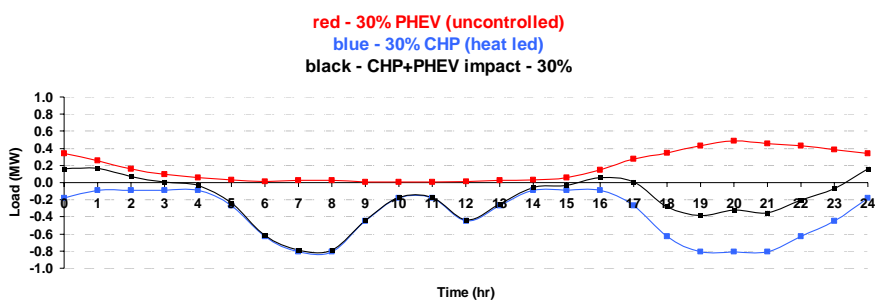

Fig. 7. Illustrates the combined effect PHEV and CHP units have on the power load variations for case 4 . The black line represents the sum of PHEV uncontrolled demand and the heat led CHP generation.

PHEV + CHP Winter power load profile at the supply point

red - $30 \%$ PHEV (delayed)

blue - $30 \%$ CHP (heat led) black - CHP+PHEV impact - 30\%

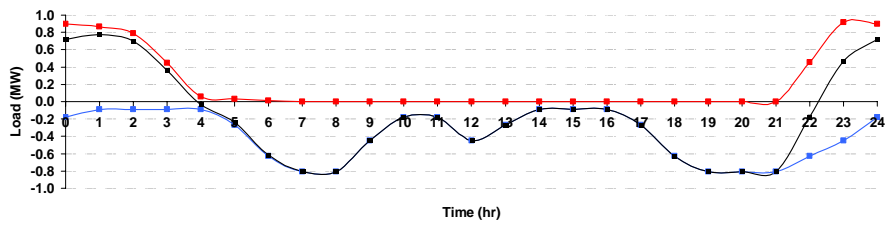

Fig. 8. Illustrates the combined effect PHEV and CHP units have on the power load variations for case 5 . The black line represents the sum of PHEV delayed demand and the heat led CHP generation.

\section{CONCLUSIONS AND FURTHER WORK}

In this paper an integrated OPF model for both natural gas and electric networks is presented. Therefore, a mathematical model is formulated as an optimisation problem to evaluate how control devices can influence energy losses. In this publication two objective functions are proposed which represent different operation strategies by the DNOs. Thus, the equations employed to represent their control devices, an OLTC and a compressor unit, in their respective networks is described. The gas and electrical infrastructures are interconnected by CHP devices embedded in the networks while PHEV units are included in the model to assess the additional burden they will have on the electric grid. An OPF solution is obtained by performing a steady-state optimisation using the gPROMS ${ }^{\mathrm{TM}}$ software tool. Various case studies are performed in distribution networks varying the penetration of both embedded technologies and the charging scenarios of the PHEV units. Results show that the benefits in applying a "loss minimisation" strategy are considerable in electric networks when compared to a "plug and forget" strategy. However, these benefits do not translate as effectively to gas networks. Overall, the OPF tool proves its value in assessing the effects DNOs can have on energy savings. Further research in this field should include the addition of thermal and power storage which allows flexibility in the provision of energy and adds to loss reduction in urban energy service networks.

\section{ACKNOWLEDGMENT}

The authors gratefully acknowledge the contributions of Carlos A. Hernandez-Aramburo in this work.

\section{REFERENCES}

[1] Department for Business Enterprise \& Regulatory Reform, "System Integration of Additional Micro-generation (SIAM)," [Online]. Available: www.berr.gov.uk/files/file15192.pdf [Accessed: Mar. 4, 2009].

[2] Department for Business Enterprise \& Regulatory Reform, "UK Energy and $\mathrm{CO}_{2}$ Emissions Projections," Energy Strategy Unit. [Online]. Available: www.berr.gov.uk/files/file26363.pdf [Accessed: Mar. 4, 2009].

[3] Carbon Trust, "Micro-CHP Accelerator," [Online]. Available: http://www.carbontrust.co.uk [Accessed: Mar. 4, 2009].

[4] Sustainable Energy Ireland, "Hybrid Electric and Battery Electric Vehicles," AEA Energy \& Environment. [Online]. Available: www.sei.ie/News_Events/Press_Releases/Costs_and_benefits.pdf [Accessed: Mar. 4, 2009].

[5] J. Fan and S. Borlase, "The evolution of distribution," Power and Energy Magazine, IEEE , vol.7, no.2, pp.63-68, March-April 2009.

[6] H.L. Willis and W.G. Scott, Distributed Power Generation: Planning and Evaluation, 1st edition, USA: Marcel Dekker, 2000, pp. 151-220.

[7] M. Pehnt, M. Cames, C. Fischer, B. Praetorius, L. Schneider and K. Schneider, Micro Cogeneration: Towards Decentralised Energy Systems. $1^{\text {st }}$ edition, UK: Springer, 2005, pp. 1-16.

[8] N. Jenkins, R. Allen, P. Crossley, D. Kirschen, and G. Strbac, Embedded Generation. $1^{\text {st }}$ edition, UK: The Institution of Electrical Engineers, 2000, pp 11-18.

[9] Department for Business Enterprise \& Regulatory Reform, "Integration of Operation of Embedded Generation and Distribution Networks," Manchester Centre for Electrical Energy. [Online]. Available: www.berr.gov.uk/files/file15122.pdf [Accessed: Mar. 4, 2009].

[10] A.D. Peacock and M. Newborough, 2006, "Impact of micro-chp Systems on Energy Flows in the UK Electricity Supply Industry”, Energy, vol. 31, pp. 1804-1818.

[11] A.D. Peacock and M. Newborough, 2007, "Controlling micro-CHP Systems to Modulate Electrical Load Profiles”, Energy, vol. 32, pp. 1093-1103.

[12] T.H. Bradley and A.A. Frank, "Design, demonstrations and sustainability impact assessments for plug-in hybrid electric vehicles", Renewable and Sustainable Energy Reviews, Volume 13, Issue 1, January 2009, pp. 115-128.

[13] H. Turton and F. Moura, "Vehicle-to-grid systems for sustainable development: An integrated energy analysis", Technological Forecasting and Social Change, Volume 75, Issue 8, October 2008, pp. 1091-1108.

[14] Tesla Roadster PHEV. www.teslamotors.com

[15] Federal Energy Regulatory Commission, "Impacts Assessment of Plugin Hybrid Vehicles on Electric Utilities and Regional U.S. Power Grids Part 1," Pacific Northwest Laboratory. [Online]. Available: www.berr.gov.uk/files/file15192.pdf [Accessed: Mar. 4, 2009].

[16] W. Kempton and J. Tomic, "Vehicle-to-grid Power Implementation: From Stabilizing the Grid to Supporting Large-scale Renewable Energy”, Journal of Power Sources, Volume 144, Issue 1, 1 June 2005, pp. 280-294.

[17] National Renewable Energy Laboratory, "Costs and Emissions Associated with Plug-in Hybrid Electric Vehicle Charging in the Xcel Energy Colorado Service Territory,” [Online]. Available: www.nrel.gov/docs/fy07osti/41410.pdf [Accessed: Mar. 4, 2009].

[18] S. An, Q. Li, and T.W. Gedra., "Natural Gas and Electricity Optimal Power Flow," in 2003 IEEE PES Transmission and Distribution Conference, Sep 7-12 2003. 2003. Dallas, TX, USA: IEEE.

[19] C. Unsihuay, J.W.M. Lima, and A.C.Z. de Souza. "Modeling the Integrated Natural Gas and Electricity Optimal Power Flow," in Power Engineering Society General Meeting, 2007 IEEE. 2007.

[20] M. Chaudry, N. Jenkins, and G. Strbac, "Multi-time Period Combined Gas and Electricity Network Optimization", Electric Power Systems Research, Volume 78, Issue 7, July 2008, pp. 1265-1279. 
[21] M. Geidl and G. Andersson, "Optimal Power Flow of Multiple Energy Carriers," Power Systems, IEEE Transactions on, vol.22, no.1, pp.145155, Feb. 2007.

[22] M. D. Galus and G. Andersson, "Demand Management of Grid Connected Plug-In Hybrid Electric Vehicles (PHEV)," Energy 2030 Conference, 2008. ENERGY 2008. IEEE, pp.1-8, 17-18 Nov. 2008.

[23] H. Lund and W. Kempton, "Integration of Renewable Energy into the Transport and Electricity Sectors through V2G”, Energy Policy, Volume 36, Issue 9, September 2008, pp. 3578-3587.

[24] S. Acha and C. Hernandez-Aramburo, "Integrated Modelling of Gas and Electricity Distribution Networks with a High Penetration of Embedded Generation," SmartGrids for Distribution, 2008. IET-CIRED. CIRED Seminar , pp.1-4, 23-24 June 2008.

[25] E. Acha, C.R. Fuerte-Esquivel, H. Ambriz-Perez, and C. AngelesCamacho, FACTS: Modelling and Simulation in Power Networks. $1^{\text {st }}$ edition, UK: John Wiley \& Sons, 2004, pp 70-72.

[26] E.S. Menon, Gas Pipeline Hydraulics. $1^{\text {st }}$ edition, New York: Taylor \& Francis, 2005, pp. 139-145.

[27] D.I. Sun, B. Ashley, B. Brewer, A. Hughes, and W.F. Tinney, "Optimal Power Flow by Newton Approach”. IEEE Trans. Power Apparatus and Systems PAS-103(10), pp. 2864-2880.

[28] A. Hawkes and M. Leach, "Impacts of Temporal Precision in Optimisation Modelling of micro-Combined Heat and Power”, Energy, Volume 30, Issue 10, July 2005, pp.1759-1779.

[29] Gproms software. www.psenterprise.com

[30] UKGDS, "United Kingdom Generic Distribution System”, [Online]. Available: monaco.eee.strath.ac.uk/ukgds/, accessed on $1^{\text {st }}$ May 2008.

[31] C. Segeler, 1968, Gas Engineers Handbook, Industrial Press, USA.

[32] N. Silva and G. Strbac, "Optimal Design Policy and Strategic Investment in Distribution Networks with Distributed Generation," SmartGrids for Distribution, 2008. IET-CIRED. CIRED Seminar, pp. 1-4, 23-24 June 2008.

\section{BIOGRAPHIES}

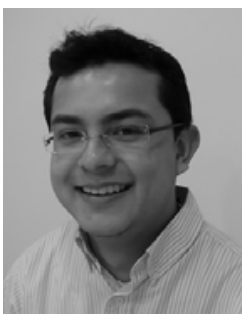

Salvador Acha (M’2001) received the B.Sc. (Eng.) degree in Electronics and Communications Engineering from Monterrey Tech (ITESM), Monterrey, Mexico, in 2003. After working in the private sector he joined the Urban Energy Systems Project at Imperial College London, London, U.K., where he is pursuing the Ph.D. degree in Electrical Engineering. His research interests include the integration of distributed generation resources, plugin hybrid vehicles, distribution management systems, and power system economics.

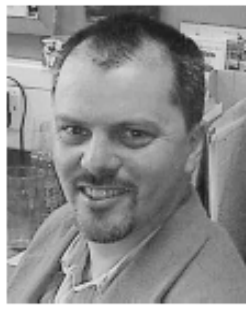

Tim C. Green (M'89, SM'03) received the B.Sc. (Eng.) (first class honours) degree from Imperial College London, London, U.K., in 1986, and the Ph.D. degree from Heriot-Watt University, Edingburgh, U.K. in 1990, both in Electrical Engineering. He was with Heriot-Watt University until 1994 and is currently the Deputy Head of the Control \& Power Research Group at Imperial College London. His research interests include power engineering, covering distributed generation, microgrids, power quality, active power filters, FACTS technology, control of power systems using FACTS devices, and active distribution networks. Dr. Green is a charted Engineer in the U.K. and a Member of the Institution of Electrical Engineers, U.K.

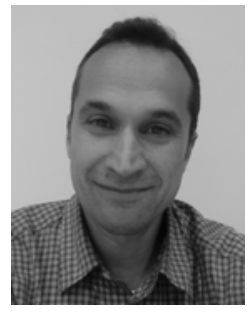

Nilay Shah obtained his Ph.D. in Chemical Engineering from Imperial College London, London, U.K. in 1992. After a period of secondment at Shell UK, he joined the academic staff of Imperial College London under various faculty roles. Since 2001 he has been a Professor of Process Systems Engineering. He undertakes his research in the Queen's Award winning Centre for Process Systems Engineering (CPSE). He is the deputy Director of CPSE, the coDirector of the BP Urban Energy System project and a Fellow of the Institution of Chemical Engineers. His research interests include the application of mathematical and systems engineering techniques to analyse and optimise energy systems, including urban energy systems and bioenergy systems. He is also interested in devising process systems engineering methods to complex systems such as large scale supply chains and biochemical processes. 